\title{
DIAGNOSTIC ROLE OF PEDIATRIC APPENDICITIS SCORE (PAS) IN APPENDICITIS OF CHILDREN
}

\author{
SK MONDAL ${ }^{1}$, AKMZ HOSSAIN $^{2}$, M RAHMAN $^{3}$, GZ HASAN $^{4}$, K HASINA $^{5}$, M NURUZZAMAN $^{6}$
}

\begin{abstract}
:
Appendicitis is one of the most common causes of acute abdominal pain in pediatrics and is the most common indication for emergency abdominal surgery in childhood. The diagnosis of pediatric appendicitis remains challenging. To evaluate the role of pediatric appendicitis score (PAS) in the diagnosis of appendicitis of children.

Methods: In this study, 200 suspected appendicitis patients attended in four private hospitals in old Dhaka city over a period of about 34 months from January 2011 to May 2014 were selected as study subjects. Patient age, sex and each of the eight PAS components were collected. Children who had PAS less than six were discharged and contacted by telephone upto 1 month to verify final outcome. Rest of the children with PAS equal or more than 6 were underwent appendectomy.

Results: Two hundred patients were assessed in this study. Out of them 67 (33.5\%) children had appendicitis and 76 (38.0\%) children had PAS equal or more than 6. In appendicitis children, maximum $(85.3 \%)$ children were in age group 10 16 years and $10(14.7 \%)$ patients were in age group 5-9 years.

Male $(73.5 \%)$ were predominant than female $(26.5 \%)$ in appendicitis children. Migration of pain, nausea and anorexia were in $43(63.2 \%), 45(66.2 \%)$ and $48(70.6 \%)$ appendicitis children respectively. Fever, cough/percussion
\end{abstract}

1. Dr.Susankar Kumar Mondal, Assistant Prof. Pediatric Surgrey BSMMU.

2. Dr. AKM Zahid Hossain, Associate Prof. Pediatric Surgrey BSMMU.

3. Dr. Mizanur Rahman, Assistant Prof. Pediatric Surgrey. Khulna Medical College \& Hospital.

4. Dr.Gazi Zahirul Hasan, Associate Prof. Pediatric Surgrey BSMMU.

5. Dr. Kaniz Hasina, Associate Prof. Pediatric Surgrey, DMCH

6. Dr. Md. Nuruzzaman, Assistant Prof. Pediatric Surgrey BSMMU

Correspondence to : Dr. Susankar Kumar Mondal, Assistant Prof. Pediatric Surgrey BSMMU, E-mail: dr.sankar71@gmail.com tenderness and tenderness in RLQ were in 37 (54.4\%), 52 $(76.5 \%)$ and $59(86.8 \%)$ appendicitis children respectively. Leukocytosis andneutophilia were present in $42(61.8 \%)$ and $46(67.6 \%)$ appendicitis children respectively. The sensitivity, specificity, positive predictive value (PPV), negative predictive value (NPV) and accuracy rate of PAS were $80.6 \%$, $83.5 \%, 71.1 \%, 89.5 \%$ and $82.5 \%$ respectively.

Conclusion: Paediatric Appendicitis Score is a good tool but not good enough for diagnosis of paediatirc appedicitis. It cannot be recommended for diagnosis of paediatric appendicitis because its negative appendicectomy rate as well as wrongly discharged rate is high.

Key wards: PSA, Appendicitis.

\section{Introduction}

Appendicitis results from an acute inflammation of the appendix. It is most common in 10 to 19 years old age group (233/100,000 population annually $)^{1}$. The classic presentation for appendicitis involves the onset of vague epigastric or periumbilical pain followed by anorexia, nausea or vomiting and the migration of pain to the right lower quadrant (RLQ). It is one of the most common causes of acute abdominal pain in pediatrics and is the most common indication for emergency abdominal surgery in childhood ${ }^{2}$. The diagnosis of appendicitis is problematic in children because many present with signs and symptoms that mimic other common causes of abdominal pain. When it presents with typical symptoms, it is relatively easy to diagnose ${ }^{3}$. The overall negative appendectomy rate among all children is suggested to be $8.4 \%{ }^{4}$. Recent studies have proposed different methods to treat children presenting to the emergency department (ED) with symptoms suggestive of appendicitis $^{5,6}$. Clinical scores used in these studies 
have relied on historical, physical examination, and laboratory findings. Ideally, a clinical score could accurately distinguish those patients that need immediate operative care from those that may benefit from further investigation or observation. Two pediatric appendicitis scoring systems, published by Alvarado ${ }^{7}$ and Samuel ${ }^{8}$ are the most widely referenced in the literature ${ }^{6}$. The PAS was introduced by Maden Samuel in 2002 as a way to stratify children's risk of having appendicitis when they present with abdominal pain. The scoring system consists of 8 findings ( 6 worth 1 point, and 2 worth 2 points for a total score of 10 points). Since Samuel's inception, several studies have addressed the sensitivity and specificity of this scoring system and attempted to develop strategies for it's use, mostly in deciding whom to take to the operating room without imaging, whom to image, and whom to send home. The primary aim in this study was to evaluate the diagnostic accuracy, sensitivity and specificity of pediatric appendicitis score (PAS) in the evaluation of appendicitis.

\section{Materials and methods}

This study was conducted in four private hospitals in old Dhaka city over a period of about 34 months from January 2011 to May 2014. A total of 200 clinically suspected patients of appendicitis were taken as study subjects. After obtaining informed consent, a data collection form contained information about patient age, sex, date and time of the examination, the date and time of the onset of symptoms, and each of the eight PAS components (Table 1) was completed. All data collection forms were completed prior to obtaining any imaging investigations. Children who had PAS less than six were discharged and contacted by telephone upto 1 month to verify final outcome. Rest of the children with PAS equal or more than 6 were underwent appendectomy. Discharged children or their parents were asked if they or their child had an appendectomy at the same hospital or elsewhere since their discharge. If a patient underwent an appendectomy at the study site or elsewhere, the medical record was obtained and the pathology was reviewed. Appendicitis was defined as appendectomy with positive histology. A negative appendectomy was defined as an appendectomy with negative histology. Missed appendicitis was defined as a child who was discharged home from the hospital but within 1 month had an appendectomy with positive histology. For analysis, the patients were separated into two groups: those with histology-confirmed appendicitis and those without appendicitis. The latter group included children who underwent appendectomy but who had negative histology. Data were analyzed by simple statistical method (percentage) and presented in the form of frequency distribution using Statistical Package for the Social Sciences SPSS 15.0 for Windows.

Table-I

Pediatric appendicitis score

\begin{tabular}{lc}
\hline Diagnostic criteria & Value \\
\hline Nausea/vomiting & 1 \\
Anorexia & 1 \\
Fever & 1 \\
Migration of pain & 1 \\
Leukocytosis & 1 \\
Neutrophilia & 1 \\
Tenderness in RLQ & 2 \\
Cough/percussion tenderness & 2 \\
\hline
\end{tabular}

\section{Results}

In appendicitis children, maximum (85.3\%) children were in age group 10-16 years and $10(14.7 \%)$ patients were in age group 5-9 years. Male $(73.5 \%)$ were predominant than female $(26.5 \%)$ in appendicitis children. Migration of pain, nausea and anorexia were in 43 (63.2\%), 45 (66.2\%) and 48 $(70.6 \%)$ appendicitis children respectively. Fever, cough/percussion tenderness and tenderness in RLQ were in 37 (54.4\%), 52 (76.5\%) and 59 (86.8\%) appendicitis children respectively. Leukocytosis and neutophilia were present in 42 (61.8\%) and 46 (67.6\%) appendicitis children respectively (Table-II). Out of 200 cases 76 were diagnosed as appendicitis by PAS and among them 56 were confirmed by histopathological diagnosis. They were true positive and remaining 20 cases were false positive. Out of rest 124 cases discharged from hospital, 12 children had appendicectomy within one month were false negative and 112 patients having PAS $<6$ did not have appendicectomy within one month from discharge were true negative (Table-III). The sensitivity, specificity, positive predictive value (PPV), negative predictive value (NPV) and accuracy rate of PAS was $80.6 \%, 83.5 \%, 71.1 \%, 89.5 \%$ and $82.5 \%$ respectively (Table-IV). 
Table-III

Demographic profile and PAS in the study children with and without appendicitis

\begin{tabular}{|c|c|c|c|c|}
\hline \multirow[t]{2}{*}{ Variable } & \multicolumn{2}{|c|}{ Histopathology } & \multirow[t]{2}{*}{ Total } & \multirow[t]{2}{*}{$p$ value } \\
\hline & Positive ( $n=68)$ & Negative $(n=132)$ & & \\
\hline Age & & & & $<0.001$ \\
\hline $05-09$ & $10(14.7)$ & $56(42.4)$ & $66(33.0)$ & \\
\hline $10-16$ & $58(85.3)$ & $76(57.6)$ & $134(67.0)$ & \\
\hline Gender & & & & 0.001 \\
\hline Male & $50(73.5)$ & $64(48.5)$ & $114(57.0)$ & \\
\hline Female & $18(26.5)$ & $68(51.5)$ & $86(43.0)$ & \\
\hline PAS & $7.11 \pm 1.35$ & $2.70 \pm 1.42$ & $4.20 \pm 2.51$ & $<0.001$ \\
\hline \multicolumn{5}{|l|}{ History } \\
\hline Migration of pain & $43(63.2)$ & $41(31.1)$ & $84(42.0)$ & $<0.001$ \\
\hline Nausea or vomiting & $45(66.2)$ & $70(53.0)$ & $115(57.5)$ & 0.075 \\
\hline Anorexia & $48(70.6)$ & $52(39.4)$ & $100(50.0)$ & $<0.001$ \\
\hline \multicolumn{5}{|l|}{ Physical examination } \\
\hline Fever $\left(>38^{\circ} \mathrm{C}\right)$ & $37(54.4)$ & $38(28.8)$ & $75(37.5)$ & 0.001 \\
\hline Cough/percussion tenderness & $52(76.5)$ & $27(20.5)$ & $79(39.5)$ & $<0.001$ \\
\hline Tenderness in RLQ & $59(86.8)$ & $14(10.6)$ & $73(36.5)$ & $<0.001$ \\
\hline \multicolumn{5}{|l|}{ Laboratory results } \\
\hline Leukocytosis WBC e" & & & & \\
\hline $10,000 / \mathrm{mm}^{3}$ & $42(61.8)$ & $31(23.5)$ & $73(36.5)$ & $<0.001$ \\
\hline \multicolumn{5}{|l|}{ Neutrophilia e" } \\
\hline $7,500 / \mathrm{mm}^{3}$ & $46(67.6)$ & $45(34.1)$ & $91(45.5)$ & $<0.001$ \\
\hline
\end{tabular}

Table-III

Pediatric appendicitis score compared to histology

\begin{tabular}{|c|c|c|c|}
\hline \multirow[t]{2}{*}{$\overline{\text { PAS }}$} & \multicolumn{2}{|c|}{ Histopathology } & \multirow[t]{2}{*}{ Total } \\
\hline & $\begin{array}{l}\text { Positive (Appendicitis) } \\
\qquad \mathrm{n}=67\end{array}$ & $\begin{array}{l}\text { Negative/ Treated conservatively } \\
(\text { Normal) } n=133\end{array}$ & \\
\hline$\overline{e "} 6$ & $54(27.0)$ & $22(11.0)$ & $76(38.0)$ \\
\hline$<6$ & $13(6.5)$ & $111(55.5)$ & $124(62.0)$ \\
\hline$\overline{\text { Total }}$ & $67(33.5)$ & $133(66.5)$ & $200(100.0)$ \\
\hline
\end{tabular}

Table-IV

Validity test $(n=200)$

\begin{tabular}{lrc}
\hline Validity test & Value (\%) & $95 \% \mathrm{Cl}$ \\
\hline Sensitivity & 80.6 & $71.3-87.8$ \\
Specificity & 83.5 & $78.8-87.1$ \\
Positive predictive value (PPV) & 71.1 & $62.9-77.4$ \\
Negative predictive value (NPV) & 89.5 & $84.5-93.4$ \\
Accuracy & 82.5 & $76.3-87.3$ \\
\hline
\end{tabular}

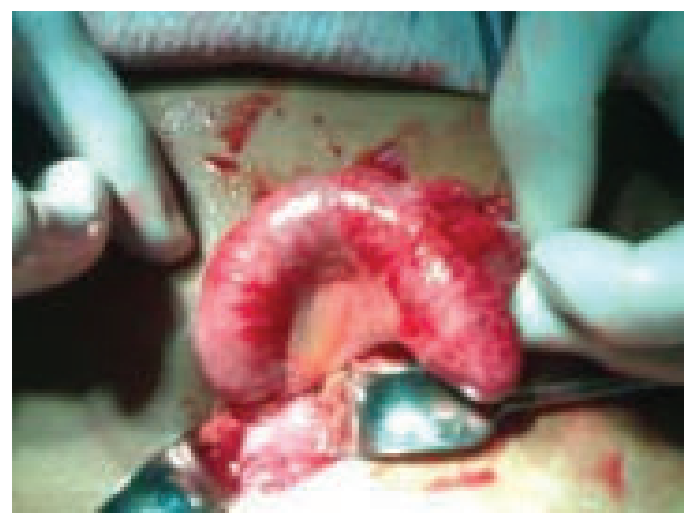

Fig.-1: Inflammed Appendix 


\section{Discussion}

The PAS is a relatively new scoring system which relies upon simple points in the history and examination of a patient. It is scored out of ten with a score of five or less excluding appendicitis, and a score of six or above making a true case of appendicitis highly likely. In this study most of the appendicitis children were male and age range was 10-16 years ${ }^{9,10}$. Routhrock and Pagane stated that anorexia, migration of pain to right lower quadrant (RLQ) and onset of fever and vomiting was observed in fewer than $60 \%$ of patients ${ }^{11}$. In this study leucocytosis and neutrophilia were present in $61.8 \%$ and $67.6 \%$ of the appendicitis cases respectively. A study of 225 patients by Doraiswamy ${ }^{12}$ showed leucocytosis in $42 \%$ and neutrophilia in $96 \%$ of the cases. Drinkovi $\mathrm{N}$ stated ${ }^{10}$ that the frequency of the studied symptoms (vomiting, leukocytosis) range from $49.4 \%$ to $64.8 \%$. The overall sensitivity, specificity, PPV, NPV and accuracy were found $80.6 \%, 83.5 \%$, $71.1 \%, 89.5 \%$ and $82.5 \%$ respectively, which showed that PAS has a high sensitivity and specificity in diagnosing paediatric appendicitis. The overall sensitivity and specificity rates were almost same with the values drawn by Attia ${ }^{13}$, Goulder and Simpson ${ }^{14}$ and Samuel ${ }^{8}$, whose sensitivity values varied from $72.0 \%-100.0 \%$ and specificity ranges varied from $60.0 \%-92.0 \%$.

\section{Conclusion}

In our study, $22(11.0 \%)$ of children underwent a negative appendectomy and $13(6.5 \%)$ of children with appendicitis were sent home without appendectomy. The PAS cannot be recommended as it would lead to an unacceptable risk of wrongly discharging or delaying necessary surgery in patients with appendicitis in children.

\section{References}

1. Addiss DG, Shaffer N, Fowler BS et al. The epidemiology of appendicitis and appendectomy in the United States. Am J Epidemiol 1990;132:910-25.

2. Rudolph CD, Rudolph AM, eds. Rudolph's Pediatrics. 21st ed. New York, NY: McGraw-Hill, Medical Publisher; 2003.
3. Bari MR, Al-Azad S, Chowdhury $\mathrm{N}$ et al. Role of Ultrasonography in the Diagnosis of Appendicitis with Peroperative and Histopathological Correlation. Bangladesh Journal of Radiology and Imaging 2009;17(1):10-4

4. Smink DS, Finkelstein JA, Kleinman K and Fishman SJ. The effect of hospital volume of pediatric appendectomies on themisdiagnosis of appendicitis in children, Pediatrics, 2004;113(1):18-23.

5. Kharbanda AB, Taylor GA, Fishman SJ, et al. A clinical decision rule to identify children at low risk for appendicitis. Pediatrics.2005;116:709716.

6. Kwok MY, Kim MK, Gorelick MH. Evidencebased approach to the diagnosis of appendicitis in children. Pediatr Emerg Care. 2004; 20:690698.

7. Alvarado A. A practical score for the early diagnosis of acute appendicitis. Ann Emerg Med. 1986;15:557-564.

8. Samuel M. Pediatric appendicitis score. J Pediatr Surg. 2002;37: 877-881.

9. Humes DJ and Simpson J. Acute appendicitis. BMJ. 2006;333(7567):530-4.

10. Drinkovi N. Age distribution and clinical characteristics in acute appendicitis. Vojnosanit Pregl, Military-medical and pharmaceutical review 1991 Mar-Apr;48(2):115-9.

11. Rothrock SG, Pagane J. Acute appendicitis in children: emergency department diagnosis and management. Ann Emerg Med. 2000;36(1): 39-51.

12. Doraiswamy N.V. Leucocyte counts in the diagnosis and prognosis of acute appendicitis in children. Br J Surg 1979; 66:782.

13. Attia MW. The Paediatric Appendicitis Score (PAS) was useful in children with acute abdominal pain. EBM. 2009; 14(1):26

14. Goulder F and Simpson T. Pediatric appendicitis score: A retrospective analysis. J Indian Assoc Pediatr Surg. 2008;13(4):125-127 